\title{
Activating NTRK Family Fusion Gene Mutation
}

National Cancer Institute

\section{Source}

National Cancer Institute. Activating NTRK Family Fusion Gene Mutation. NCI Thesaurus.

Code C150438.

A fusion mutation involving an NTRK family gene that causes the encoded receptor tyrosine kinase and its downstream pathways to be constitutively activated. 